\title{
Rethinking the Epistemic Case against Epistocracy
}

\begin{abstract}
In this article, I focus on epistemic arguments which suggest that disenfranchising persons on the grounds of incompetence is likely to produce epistemically sub-optimal decisions. I suggest three ways in which such arguments can be strengthened. First, I argue that these could benefit by distancing themselves from the 'best judge' principle, according to which every person is the best judge of her or his own best interests. Instead, I suggest that it can rely on a more modest 'necessary interlocutor' principle whereby persons ought to be included within deliberations over their interests. Second, I argue that the epistemic case against competencebased disenfranchisement could benefit by focusing further on the specific epistemic costs that follow from the exclusion of already disadvantaged social groups from the deliberative process. Such exclusion is likely to worsen the 'strategic avoidance' to which privileged social groups are in any case susceptible. Finally, I argue that current epistemic critics of epistocracy ignore how its basis for exclusion entails consequences that are relevant to our assessment of its justifiability. I emphasise how disenfranchisement on the grounds of incompetence would vitiate deliberation by devaluing those excluded from the vote.
\end{abstract}

\section{Keywords}

Epistocracy; Epistemic Democracy; Democratic Theory; Social Epistemology; Strategic Avoidance 


\section{Rethinking the Epistemic Case against Epistocracy}

In recent times, we have seen a rise in academic work on epistocracy, the notion that political power ought to be held primarily, or even exclusively, by competent persons. Whereas epistemic critiques of democracy have had a long tradition in political theory, recent work suggests that democratic arrangements ought to be eschewed altogether as a result of their shortcomings. Outside the academy, frustration with voters' ignorance and unreasonableness has come to the fore due to the rise of populism, evidenced in the British referendum on membership of the European Union, and the electoral triumph of Donald Trump in the United States. Many commentators view such events as an indictment of democracy, echoing the call for the exclusion of 'incompetent' voters (Graham, 2002; Granderson, 2011; Ziliotti and Bell, 2014; Harsanyi, 2016; Brennan, 2016).

In this article, I focus on epistemic arguments which suggest that disenfranchising persons on the grounds of incompetence is likely to produce epistemically sub-optimal decisions. I suggest three ways in which such arguments can be strengthened. First, I argue that they can be untethered from the controversial 'best judge' principle, according to which each person is the best judge of their own interests. Second, I suggest that epistemic arguments against epistocracy are currently insensitive to the nature of the groups that would be excluded on the grounds of incompetence. Such arguments would remain unchanged were epistocracy to disenfranchise privileged persons rather than already disadvantaged persons. I argue that a stronger critique of epistocracy ought to focus on distinctive epistemic obstacles faced by socially privileged persons. Third, I argue that current epistemic critics of epistocracy ignore how its basis for exclusion entails consequences that are relevant to our assessment of its justifiability. Their criticisms would, for instance, remain the same had this exclusion been brought about in a random manner. Instead, I emphasise the deliberative costs that follow from the exclusion of disadvantaged groups qua incompetent.

\section{Epistocracy and the Distribution of Competence}

How the need for expertise can be incorporated into the design of political questions has long posed a challenge for political philosophers and constitution-makers. Alfred Moore rightly notes that the question of expertise might be raised at either of two levels of institutional design. At the first level, one might worry about 'master knowledge', which consists in the 'good of the community, that could be known by a specific elite' (Moore, 2017, p. 18). The second dimension of expertise pertains to 'subordinate' knowledges. Experts at this level are limited in their knowledge. 'The general knows how to go to war but not whether to go to war. The rhetorician knows how to persuade an audience but not what it is good to persuade them of', Moore (2017, p. 19) argues. The second level comprises what Kasper Lippert-Rasmussen calls 'issue-sensitive' expertise (2012, p. 247). Experts at the first level-the guardian class in Plato's ideal regime, for instance-instruct and coordinate subordinate experts. Whereas political theorists have ordinarily rejected the notion of guardianship, or first-level experts, they have dedicated considerable attention to an epistemic division of labour, and the appropriate bounds of epistemic authority of subordinate experts. The idea of guardianship has been 
replaced with the norm of self-government. Rather than seeking out 'master' experts, who have exclusive access to the good of the community, political theorists have insisted that persons ought to be treated as the best judges of their own interests. This consensus, however, has been threatened in recent times by tumultuous political events and research in the social sciences on citizens' levels of knowledge.

This article is concerned with questions about first-level expertise, leaving open the question about the epistemic division of labour and limitations upon the scope of expertise on specific issues like climate change or international trade, which have received extensive treatment elsewhere (See, for instance, Guston, 2005; Miller and Whitford, 2016). Instead, I focus on the justifiability of tilting the scales of political power in the direction of those who possess greater competence. This aim might be achieved in either of two ways. First, it may involve subjecting all persons to a competence test, and enfranchising only those who demonstrate a certain level of political competence. ${ }^{i}$ Second, it may involve giving all persons a baseline level of political influence in the form of a vote, but awarding greater voting power to competent persons relative to incompetent ones. ${ }^{\text {ii }}$ I focus on the justifiability of such mechanisms excluding or disadvantaging persons in the electoral process for legislative bodies. ${ }^{\text {iii }}$

\subsection{The Exclusion of Disadvantaged Demographic Groups}

Empirical research demonstrates that there are significant differences in political knowledge across gender, racial and ethnic groups. Blacks and Hispanics consistently score lower than non-Hispanic whites, while women score lower than men on tests for political knowledge. Disparity in political resources plays a crucial role in producing unequal distributions of political knowledge across demographic groups (Verba et al., 1993). Lower knowledge among black citizens, for instance, reflects disparities in access to sources of knowledge like schools and the workplace (Emler and Frazer, 1999). Similarly, socialisation into expectations about political knowledge, and the historical absence of certain groups from the political domain, contribute towards unequal distributions of knowledge across groups.

One might insist that we ought to design tests that are able to capture the competence of disadvantaged groups, ensuring that they are not disproportionately excluded. There would be good reasons to remain pessimistic of that approach. The surveys highlighted above have been conducted by political scientists sensitive to socio-economic disadvantage, and concerned with the most valid possible conception of competence. There is little reason to believe that designers of competence tests would do any better such that their standards would exclude fewer disadvantaged persons. ${ }^{\text {iv }}$ Further, insofar as resources are convertible into other opportunities, it is likely that advantaged groups would continue to be disproportionately included under a competence-based franchise. Jason Brennan, for instance, suggests that competence tests might spur Princeton Review-style 'coaching centres', where people would try and obtain the kind of information they need in order to obtain a vote (2011, p. 719). Such opportunities are likely to be available to already advantaged persons, giving them a disproportionate chance of faring well even on some revised competence test. Finally, it is worth recognising that epistocrats like Brennan themselves recognise that the exclusion of 
disadvantaged groups is an inescapable outcome (2016, p. 228). So, let us accept that competence tests are likely to exclude already disadvantaged persons, who have unequal access to competence.

\subsection{The Distribution of Competence and the Justifiability of Political Institutions: Two Theses}

Inequalities in competence across demographic groups raise what I call the distribution question: is it justifiable to insist upon the competence-based political exclusion of persons who lack such competence due to unjust systemic features of a society? One might respond to this question in two ways. The first response, the connection thesis, insists that there is something wrong with disenfranchising people who lack competence because of social structural injustices which they suffer. In making this argument, we might insist that the justifiability of epistocracy cannot be distinguished from whether or not competence is distributed equitably across different social groups. There seems something intuitively wrong about penalising persons for facing some disadvantage over which they have little control.

Alternatively, the epistocrat might agree it is unfair that some groups are unable to act competently because of social structural injustices. Nevertheless, that is a separate matter from whether or not epistocracy is justified. The second response can be outlined in two ways. The first, temporary separation thesis, suggests that the imposition of epistocracy despite the unequal distribution of competence is justified as a transitional measure. Given extant distributions of competence, power must regrettably be transferred to a certain demographic group for the time being. This is acceptable as a transitional measure aimed at bringing about an equitable distribution of competence. After a more or less brief period of time, the unequal distribution of competence, which gives greater power to certain disadvantaged groups, would no longer obtain. The temporariness of one group holding disproportionate power seems to undergird the suggestion that this is a regrettable choice under non-ideal circumstances. Proponents of that argument may hesitate to endorse an arrangement where some demographic group perpetually held political power. ${ }^{\mathrm{v}}$ On the other hand, one might advance a perpetual separation thesis. On this account, all that matters for the justifiability of political arrangements is their ability to deliver epistemically superior outcomes. Insofar as epistocracy performs better than available alternatives on this front, whether or not it produces an equitable distribution of competence in society is irrelevant.

\subsection{The Temporary Separation Thesis}

The temporary separation thesis is vulnerable to the objection that the establishment of epistocracy puts in place perverse incentives to block equitable distributions of competence. Consider the argument against educational qualifications in the aftermath of abolition in America. Critics argued that this would provide an incentive to keep the formerly enslaved population in a state of ignorance. As one legislator argued, '[S] uppose that after adopting this educational qualification, [a state] should fail to provide that these people whom we now know to be ignorant, shall hereafter be educated, should simply let them severely alone? Or suppose that they interpose such restrictions by indirect laws as to practically prevent them from being 
educated'. Such criticisms were underpinned by recognition of the idea that the domain of education is frequently the subject of intense political and theoretical controversy partially because of the extent to which it can affect persons' opportunities in life. As such, those in a privileged position have a strong incentive to retain their hold over education. By linking education with political power, epistocracy strengthens an already strong incentive for those in positions of privilege to resist a more equitable distribution of education. In other words, whatever other reasons there exist for wanting to retain unequal distribution of education, epistocracy adds to that list a fairly compelling reason - the retention of political power.

The epistocrat might object that epistocracy, like democracy, rests on the assumption that political agents do not care merely for their own interests (See, for instance, Brennan, 2018, p. 66). Both arrangements require a level of trust in the voter, treating her as an agent concerned with the welfare of others. In fact, the epistocratic argument seems to go further: it attempts to eliminate potential voters who are entirely incapable of fulfilling basic moral requirements for holding political power. As a result, it would be insufficient to attribute to epistocrats the kind of self-serving motives that the argument about perverse incentives suggests. But one does not need to attribute to epistocrats the level of self-interested behaviour that instituting barriers to access would require. In order to retain political power through inequitable access to education, epistocrats need not go out of their way to establish novel obstacles. Indeed, those actions would require a certain level of self-seeking behaviour that one should be wary of attributing to individuals while thinking about which political system we ought to implement. But epistocrats need not establish such barriers to retain control over power; those barriers already exist. In order to retain political power, all they need to do is maintain status quo or not make adequate attempts to displace it considerably. These omissions do not require us to make particularly strong assumptions about epistocrats' motives as in the case of worries about institution of new barriers. But if one need not attribute any tremendous self-seeking tendencies for maintaining unequal distributions of knowledge, one would have to assume high degrees of motivation for epistocrats to actively dismantle it.

What critics of the educational qualification in America said about the distribution of formal education can be applied to access to political competence more broadly conceived. In an unjust society, where the distribution of resources required for competence is skewed against disadvantaged groups, there is reason to believe that epistocracy would fail in bringing about equitable distribution of political knowledge. Those enfranchised under epistocracy would have to possess a particularly high degree of motivation to undermine status quo. They would have to perform the considerably demanding task of dismantling structures that privilege them in order to bring about the required redistribution.

The epistocrat might now respond in two ways. Firstly, she could insist that we ought to view persons enfranchised by epistocracy as motivated by altruistic considerations. Not only do they eschew self-seeking behavior, but they actually undertake the more motivationally demanding task of attempting to redistribute resources to disadvantaged groups, in a way that ensures that competence is found equally among all demographic groups. Further, the epistocrat could retreat to what I have called the perpetual separation thesis, insisting that there is little reason 
to worry about which demographic groups hold political power as long as they continue to deliver epistemically superior outcomes.

\subsection{The Value of Epistemic Arguments against Epistocracy}

At this point, the value of epistemic arguments against epistocracy is most evident. Generally speaking, such epistemic arguments-which I explore in greater detail shortly-suggest that the political exclusion of certain groups is likely to produce decisions that are epistemically flawed. These arguments help respond to both objections highlighted above. First, they allow us to criticise epistocracy without having to attribute self-seeking behaviour to the actors it enfranchises or advantages. It is possible to insist that epistocracy is unjustified because of its epistemic weaknesses rather than the absence of appropriate motivations in the actors it favours in the distribution of political power. Crucially, epistemic arguments offer a case against the perpetual separation thesis as well. Our argument against the temporary separation thesis was limited to demonstrating why epistocracy would fail to bring about equal distribution of competence. It relied on the idea that such distribution served as a proceduralist side constraint on epistocratic arrangements. However, epistemic critiques allow us to reject epistocracy on purely instrumentalist grounds, engaging with the perpetual separation thesis on its own terms. They allow us to argue that 'democracies and their procedures are, all things, considered, a better epistemic bet than expertocracies’ (Landemore, 2014, p. 192).

Despite its intuitive implausibility, there are good reasons to engage with the perpetual separation thesis. After all, it offers exactly the kind of conclusion which hard-nosed instrumentalism about political arrangements would entail. As indicated previously, instrumentalist perspectives like these have been on the rise in the aftermath of recent political events around the world. Significantly, in certain non-Western democracies, they have influenced constitutional design as well. In Pakistan and India, for instance, laws have been enacted to exclude uneducated persons from political office despite the acknowledgment that formal education was inaccessible for many of those who were excluded as a result. ${ }^{\text {vi }}$ Further, it is worth recognising that it is not just epistocrats, but also epistemic democrats, who find themselves vulnerable to the conclusion that this article attempts to resist. If the relevant dimension in assessing competing political arrangements is indeed their epistemic performance, then it may not actually matter that this entails the exclusion of unjustly disadvantaged groups. Landemore, for instance, insists that assuming political equality as a guiding principle, rather than defending it on epistemic grounds, appears to be an 'endorsement of motivated reasoning' (2014, p. 192). This article's emphasis on the epistemic dimension of political institutions should not be taken to suggest that this is all there is to normative democratic theory. Instead, it takes seriously the notion that we should not cede the instrumentalist argument to the anti-democrat, allowing him to insist that from this perspective, democracy has little value. This is compatible with insisting that, ultimately, the value of democracy cannot be reduced to its epistemic potential.

There is another reason why the arguments urged by the epistemic case against epistocracy matter from an instrumentalist perspective. If, as proponents of this case insist, epistocracy is 
likely to produce epistemically sub-optimal decisions, then part of this failure would consist in their inability to correct injustices in the distribution of competence. This renders the epistemic flaws of epistocracy self-perpetuating. This vicious cycle underscores an important respect in which epistocratic disenfranchisement differs from the imposition of age qualifications for the vote. Lippert-Rasmussen, for instance, advances what he calls the 'time-sensitive privileged knowledge status claim': 'For any demos and any given time, it is true that there is some group of people which is different, extensionally speaking, from the demos and which knows the normative standards better than others and, thus, knows better what the decisions that conform to those standards are' (2012, pp. 246-47). Whether or not age qualifications result in better outcomes, their epistemic performance has no bearing on who they exclude. Indeed, it might be the case that age qualifications make children worse-off, affecting their long-term interests. However, they cannot prevent children from acquiring the basis for political inclusion, namely the stipulated age threshold. On the other hand, epistocratic arrangements not only produce epistemically worse decisions, but in doing so, they also maintain unequal distributions of competence across demographic groups. As a result, they reproduce the conditions for their epistemic failure.

\section{(2) Epistemic Critics of Epistocracy}

Having outlined the promise of epistemic arguments against epistocracy, I now examine them in greater detail. The first of these, David Estlund's 'demographic objection to epistocracy' insists that 'The educated portion of the populace may disproportionately have epistemically damaging features that countervail the admitted epistemic benefits of education’ (2003, p. 62). Estlund reminds us that access to knowledge is 'disproportionately the privilege of members of certain races, classes, and (formerly) genders. And even in a more ideal society, there may well be demographic patterns that make the pool of university applicants less than statistically representative' (ibid.). This argument focuses on the poor outcomes of unjust distributions of education. It insists that because epistocracy would entail the systematic overrepresentation of some groups and underrepresentation of others, it is likely to produce substantively unjust outcomes; such outcomes are likely to favour advantaged groups while further disadvantaging already disadvantaged groups. There also is no easy way of correcting for the underrepresentation of certain races, classes and genders. As Estlund argues, the demographically adjusted group of educated persons may still have some epistemically distorting feature or another, which travels with education (2008, p. 216). Further, we need not attribute any perverse motives to advantaged groups. Estlund insists that even if people act with good will rather than the neglect of others' interests, they are inevitably biased by their race, class and gender.

A second epistemic argument can be found in the work of Hélène Landemore, who insists that we ought to focus on the collective intelligence of a political arrangement rather than the individual competence of its members. Although above average competence might be helpful in some respects, the perspective of experts might be limited in others, resulting in common blind-spots. ${ }^{\text {vii }}$ Her suggestion relies upon what is known as the Diversity-Trumps-Ability 
theorem. The emphasis on cognitive diversity leads to the idea that legislative assemblies should be numerically large:

My contention is that the cheapest, simplest way to ensure great cognitive diversity is by including more people in the group of decision-makers. This is so because numbers will naturally increase cognitive diversity. I say "naturally" on the (I think) plausible assumption that cognitive diversity is normally present in any typical group of human beings, since different people come into the world equipped with different cognitive toolboxes (Landemore, 2012). ${ }^{\text {viii }}$

The task I perform in this article is to strengthen both arguments in three ways, enabling them to offer a more robust instrumentalist response to the distribution question. First, I argue that the epistemic case against epistocracy need not rely on the principle that each person is the best judge of their own interests. Instead, it is possible to draw this case by appealing to a significantly weaker idea, the 'necessary interlocutor principle', which suggests that others might be able to understand our interests better than ourselves, but that we ought to be included in deliberation over our own interests. Second, I argue that epistemic arguments can be strengthened by paying closer attention to the kind of demographic groups epistocracy would privilege in the political process. As of now, such arguments seem insensitive to whether power is awarded to disadvantaged or privileged social groups. The exclusion of any group is viewed as epistemically suspect because it is seen as precluding adequate consideration of its views. Instead, I propose focusing on the distinctive epistemic obstacles that privileged social groups face in accessing the interests of disadvantaged persons. Third, I argue that we ought to pay closer attention to the basis for exclusion under an epistocratic arrangement. Current epistemic arguments focus merely on the fact of exclusion in an epistocracy rather than the grounds for this. They are unable to show what is distinctively wrong with the exclusion or marginalisation of persons on the grounds of incompetence, rather than, say, a lottery which produced a randomly selected legislative body. I argue that the crucial difference between such cases lies in epistocracy's categorisation of persons as competent or incompetent, and the subsequent devaluation of disadvantaged persons' claims this is likely to entail.

Note that my aim in this article is merely to strengthen existing epistemic arguments rather than defending them de novo. In response to the revised epistemic case, the epistocrat might suggest that deliberation which includes epistemically incompetent agents will fare worse than that conducted between epistemically competent ones. Indeed, competent actors might have their blind-spots, which render deliberation between them sub-optimal. But the epistocrat might insist they would nevertheless fare better than a deliberative body that included incompetent persons. In her work, Hélène Landemore provides a detailed defence of inclusive deliberation, insisting that cognitive diversity matters a great deal more than individual ability from an epistemic perspective (2013, pp. 89-117). Her work suggests that democratic deliberation under ideal settings can enlarge the pool of ideas, weed out good from bad arguments, and facilitate better outcomes than less inclusive deliberative procedures. This article does not aim at rehearsing such arguments and demonstrating why democratic deliberation is a safer bet epistemically than its epistocratic counterpart. Instead, it merely aims at strengthening certain aspects of the epistemic argument for democracy. My own 
contribution, then, should be read alongside her detailed defence of the epistemic superiority of inclusive deliberation over epistocratic decision-making. ${ }^{\text {ix }}$

\section{(3) Dispensing with the Best Judge Principle}

Several democratic theorists rely on what is known as the 'best judge principle' in their defence of democratic institutions. ${ }^{x}$ David Estlund's demographic objection, too, tacitly relies on this principle. Estlund argues that even if persons advantaged by epistocracy gave 'full and fair weight to the interests of everyone, to the best of their ability', they would be limited by 'their knowledge and experience of what those interests are' $(2008,216)$. This would prevent due consideration of the interests of those disenfranchised by epistocracy. The underlying idea seems to be that people themselves are the best judges of their interests, whereas all others are epistemically deficient in this respect.

Although it is not possible to consider them exhaustively, there are good reasons to be sceptical towards the best judge principle. First, as critics have argued, our actions, driven by weakness of will, can distort beliefs about our interests. We may find ourselves unable to do what is necessary to pursue our self-perceived goals when the time comes. In such cases, we might try and avoid cognitive dissonance by altering our beliefs, and treating interests that we do not have the heart to act upon as not being our interests at all. Further, others have emphasised our ability to misjudge our interests when this involves probability calculations. Such calculations are often vitiated by our unwarranted optimism about our own life prospects, discounting the probability of risk to ourselves. Finally, critics also argue that the best judge principle fails to appreciate the extent to which persons demonstrate an irrational bias towards present over future interests. ${ }^{\text {xi }}$

It might, of course, be possible to rescue the best judge principle from such arguments. Rather than pursuing that strategy, I will demonstrate that the epistemic case against epistocracy need not rely on this controversial principle at all. Instead, it is possible to replace it with a more modest account of the relationship between persons' interests and their knowledge of their interests, which I call the necessary interlocutor principle. Contrary to the best judge principle, the necessary interlocutor position concedes that others might be able to judge our interests better. Yet, it insists that others must engage us as interlocutors in deliberation over our interests. ${ }^{\text {xii }}$ The principle requires fairly exhaustive deliberation with those whose interests are at stake, insisting that decision-makers must test the validity of their judgments against claims made those persons. There are at least two reasons why this engagement demanded by the necessary interlocutor position is warranted on epistemic grounds: first, in order to obtain adequate information about persons' circumstances, and second, for better insight into their mental states that are relevant to decisions about their interests.

The idea that the pursuit of interests requires knowledge of persons' objective circumstances is relatively uncontroversial. However, one might dispute the idea that we are best judges of those circumstances. I think it is nevertheless possible to make the weaker claim that there are some aspects of our circumstances for which we have greater insight than others. In several 
cases, persons' interests could pertain to aspects of social life from which others are excluded. This might include domains from which others remain altogether immune: for instance, having to navigate through a corrupt machinery in the distribution of welfare benefits. On the other hand, this may also include domains which others, too, participate in, but experience in very different ways. A white student from a well-off family could experience her university education very differently from an ethnic minority student from an economically deprived area. The significance of persons' knowledge about their own circumstances is particularly apparent once we recognise the dynamic nature of social structural processes. Even if we obtain insight into the kind of injustice some persons face, but from which we ourselves are immune, we cannot be sure that our judgments are valid over time. Persons immediately affected by unjust social structures can serve as an important epistemic resource, alerting us to new forms of injustice that require attention. This claim does not suggest that I have an overall better understanding of my objective circumstances, nor does it recommend that others cannot obtain insight into those aspects over which I have privileged access. Instead, it merely insists that, given my greater insight into some aspect of my circumstances, I should be included in deliberations over my interests if others' judgments about them are to be sound.

Secondly, there is at least one kind of knowledge to which my privileged access is relatively uncontroversial. Most people would agree that I have better insight than others into my own mental states, such as my anxieties, emotions or attitudes (Wilkinson, 1996). Less obvious is the relevance of such states in assessments of my interests. If my actual interests are independent of what I desire, then it appears that my mental states have little value in evaluating how to best serve my interests. But this conclusion would be too hasty. Although our desires and beliefs about our interests can be mistaken, there are various conditions under which they can nevertheless be relevant in assessments of our interests. As Joseph Raz argues, our inclinations can play an important role in determining the right course of action for ourselves. 'Many of our decisions, in matters small and large, are under-determined by reason', he argues (1986, p. 388). In such circumstances, our inclinations - having come to care about one thing rather than another — can settle, what was prior to our commitment, unsettled. Further, the performance of particular strategies aimed at securing my interests can depend at least in part on my attitude to such attempts. A strategy might fail because I do not lend it adequate support or because I proactively try and vitiate it. Another method, formulated after having consulted me, might have been more successful in securing the same end. For instance, a patient might fear intra-venous treatment, and may, as a result, be less likely to seek treatment for a certain condition. He might feel overlooked by a particular physician, and, therefore, deliberately disregard her prescribed course of treatment. These comments lend further support for the necessary interlocutor position. Insofar as knowledge of persons' mental states is relevant in judging how to best pursue their interests, they can justifiably demand inclusion in deliberation.

The principle defended here ultimately demands only the inclusion of persons in deliberation over their interests. Why would this pose a problem for epistocratic disenfranchisement, which merely demands the exclusion of persons from the vote? I return to this question in Section 5.

\section{(4) Distinctive Epistemic Challenges for Socially Advantaged Groups}


The necessary interlocutor principle underscores the need for persons to deliberate with us if they are to adequately access our interests. It is insensitive, though, to the social position of given demographic groups. It serves as a general principle, emphasising the need for deliberative engagement with any social group whose interests are at stake in a given decision. But, as I argue in this section, socially privileged groups attempting to understand the interests of disadvantaged persons face certain distinctive challenges which require further attention.

Both, Estlund and Landemore appropriately note that political outcomes would incur epistemic costs because of the exclusion of certain demographic groups that epistocracy would entail. Estlund suggests that these epistemic costs result from biases persons are likely to hold towards their own interests even if they were to act in an appropriately motivated manner. Similarly, Landemore points to the loss of perspective that political exclusion entails. She insists that irrespective of their other epistemic strengths, all political actors, including experts, are limited by the perspective they occupy on the social world. In order to perform well collectively, they must ensure that the gaps in their perspectives are filled in by others who see the world differently. With their focus on bias and perspectival loss, these arguments apply to whichever demographic group is excluded or disadvantaged by epistocracy. Were we to exclude privileged social groups from political deliberation, disadvantaged people in power would suffer similar epistemic blind-spots. I propose to strengthen their case by drawing attention to epistemic avoidance, which makes it particularly difficult for advantaged social groups to access the interests of disadvantaged persons. The challenge for such groups lies not so much in ignorance induced by bias or perspectival gaps, but by a need to not know certain kinds of things.

Standpoint theorists have long emphasised a particular kind of ignorance, which is attached specifically to positions of social dominance:

As a defence mechanism, those in a position of privilege are often encouraged to hide their heads in the sand like ostriches with respect to certain aspects, presuppositions, or consequences of the oppression that sustains their privilege. They need to ignore certain social realities. They need to live without having certain truths present in their minds...This form of cognitive self-protection...is not typically erected openly and consciously...It does not result from a decision or conscious effort to ignore, but from a socialization that leads one to be insensitive to certain things and immune to certain considerations. (Medina, 2012, pp. 35-36)

Feminist theorists have argued that privileged social groups are particularly vulnerable to epistemic avoidance of this sort because of the investment they have in maintaining an understanding of themselves as good persons. They wish to view themselves as ethical actors who do the right thing even as they enjoy the benefits attached to positions of social dominance under circumstances of structural injustice. Structures through which one has accumulated privilege do not ordinarily exist in a vacuum, but in a normative space where they have been justified as legitimate. Confronting privilege, then, involves exposing oneself to a great deal of cognitive dissonance, which individuals tend to avoid. 
The idea that we avoid acquiring information that could compromise our view of ourselves as moral actors is not entirely speculative. In a series of experiments, Jason Dana, Roberto Weber and Jason Xi Kuang highlight individuals' reliance on ignorance as an excuse for acting selfishly (Dana, Weber and Kuang, 2007). Their study modifies the standard version of the 'dictator game', where a player designated as the 'dictator' is asked to determine how to split an endowment (such as a cash prize) between herself and a second player (the 'recipient'). The dictator is faced with two options: A, which gives her a high payoff with a very low pay-off for the recipient, and B which gives her a slightly lower payoff than A, but gives the recipient a much higher payoff. Studies have demonstrated dictators' preference for the second option. This has been interpreted as evidence for individuals' commitment to equity, and its priority over pure self-interest. Dana et al. modify the dictator game to introduce 'hidden information' (Dana, Weber and Kuang, 2007). In this version of the experiment, the dictator does not know if choosing a higher pay-off for herself would entail a higher or lower payoff for the recipient. She is given the option of revealing this information, and knowing what the recipients obtain when she chooses a higher pay-off. Strikingly, the study reveals that dictators are more likely in this situation to choose a better deal for themselves when its consequences for others are uncertain. Although this uncertainty can be resolved in a 'costless' way by clicking a button, most dictators who act selfishly choose to remain ignorant. Dana, Weber and Kuang argue that this demonstrates people 'have an illusory preference for fairness' and 'dislike appearing unfair' (Dana, Weber and Kuang, 2007, p. 67).

There is some evidence confirming their hypothesis in real-world settings (Freddi, 2017), although there is considerable scope for further empirical research along those lines. We could, nevertheless, make some conjectures about its application outside artificial conditions. There are at least two reasons why, given what the study finds, epistemic avoidance is even more likely to take place in persons' actual social and political interactions. These relate to the process of acquiring information and the consequences that would follow from the acquisition of information.

The study discussed here mostly pertains to avoidance of information that is easily available. The designated dictators need only click a button in order to unveil information about recipients' pay-offs. Privileged social groups are rarely in that situation. Firstly, this knowledge is rarely available in one 'source' as a comprehensive bundle. Rather, we need to piece it together by engaging with a variety of sources. As Kai Spiekermann argues, this means that the epistemic avoidance we find in experimental settings 'should be even easier in real-life interactions, where we make plenty of choices to avoid information' (Spiekermann, 2016, p. 184). He argues that actual social life gives us plenty of opportunities for failing to find a relevant 'piece' of information about the impact of our practices on others' circumstances: 'Whether we read or not read a newspaper article, watch or not watch a TV programme, talk or not talk to an acquaintance-we take all these decisions on a daily basis, and often we have an inkling whether we can expect to learn something that might be 'uncomfortable' news for us' (ibid.). Moreover, our internalised beliefs and assumptions contribute to making ignorance hard to overcome. The cognitive tools people use to interpret their experiences of the world are 
themselves social productions, which are shaped by prevalent relations of power. These include the 'background beliefs and the conceptual grid' through which we 'perceive and make sense of what they see, hear and read' (Hayward, 2017, p. 25). Rather than updating our conceptual tools when confronted with empirical data which challenges them, we 'interpret the data through the grid of the concepts in such a way that seemingly disconfirming, or at least problematic, perceptions are filtered out or marginalised' (Mills, 2007, p. 25). Thirdly, stereotypes generated by unjust social structures impose cognitive costs even for conscientious actors who wish to act in an epistemically praiseworthy manner. Research demonstrates that such actors expend considerable cognitive effort in suppressing response-tendencies which are activated through implicit associations (Richeson and Shelton, 2007, p. 317). These, then, are very different epistemic circumstances from the click of a button which is all one needs to reveal information about the disadvantage our actions impose on others in the experimental setting. Insofar as acquiring information in the real-world is costlier, the likelihood of epistemic avoidance seems even stronger there.

Note also a difference in the likely consequences of not engaging in epistemic avoidance. The experimental study discussed above pertains to avoidance that takes place while one is deciding some future course of action. At stake in the experiment is a promised sum of money which the dictator will have to forgo if she un-masked relevant information about its impact on others. In the real world, however, motivations for avoiding information apply to situated selves embedded within given social structures from which they benefit. Strategic avoidance does not just help retain those privileges in the future-although, that, too, is important. Rather, it also prevents disruption of the practices and habits that these structures entail. Some of these practices might be constitutive of our social identities. Consider, for instance, Catherine, a white middle-class parent who moves to a suburb and sends her child to a racially exclusive school because of the greater economic opportunities it offers. ${ }^{\text {xiii }}$ She may not have acted in a racist manner towards anyone and may well prefer racially integrated schools. However, she contributes to upholding a racially segregated system of education which distributed life chances unequally. Catherine may consider herself a doting mother and take pride in what she does for her children. She may have accumulated savings over years to move to the suburbs for them. She has good reason to avoid confronting the implications of her actions for racially disadvantaged parents and their children. If she were to do so, she would face two further options: giving up her image of herself as a fair person, or reversing practices that are constitutive of her self-image as a doting mother. The experimental studies cited above appropriately point to epistemic avoidance as a way of avoiding dissonance reduction. My point is that this is even more likely in real world situations where the alternative is disrupting deep-rooted practices that are closely connected with one's identity. ${ }^{\text {xiv }}$

Epistocrats might respond by insisting that their proposals attempt to include only those persons who do not affirm false beliefs and avoid familarising themselves with true ones. As a result, it is good for disadvantaged groups if epistemically incompetent persons within privileged demographic classes are disenfranchised. This will make it less likely that those in charge of decisions are people under the influence of false ideological beliefs. Those who are unable to engage in rational revision of their beliefs due to self-defence mechanisms are likely 
to lose the right to vote under an epistocratic regime. But I do not think this is an adequate response. This is because a competence test is unable to check for epistemic avoidance properly understood. To see why, consider two features of epistemic avoidance. Firstly, it involves escaping contexts or domains where one's beliefs might be subject to discomforting scrutiny. Epistemic avoidance does often imply that persons are unable to revise their beliefs since doing so puts them in a position of discomfort, as when they must acknowledge their undeserved privilege. However, avoidance is not always a matter of failing to secure the uptake of critical perspectives of disadvantaged persons. It often goes deeper-as when persons avoid conversations that interrogate or might potentially interrogate their privilege. Here, 'not needing to know' does not involve merely remaining unresponsive to contestation, but escaping contexts where one might be forced to engage in it. Secondly, and following from the first point, epistemic avoidance is compatible with moments of recognition of injustice. Persons who adopt this strategy can, nevertheless, from time to time, acknowledge the unjust nature of the structural processes from which they benefit. We may know fully well the magnitude and moral urgency of the refugee crisis in Syria, but let this recede into the background. If we were to, indeed, treat it with the urgency we know it deserves, this would demand radical changes in our practices. As a result, we often simply omit dwelling upon certain situations, and factoring them into our judgments about actions. This does not mean we do not know about them, or could not demonstrate knowledge when called to do so. But we choose to avoid reflecting upon these in a routine manner, especially when evaluating how we ought to act.

Note that the argument outlined here does not rely on an attribution of self-seeking behavior to those enfranchised under epistocracy. I have suggested that what epistocrats lack is the motivation to engage in an inquiry about how structural injustice can be rectified. This is compatible with their acting in accordance with their conception of what is the best way of advancing the interests of disadvantaged persons. That is, they may see themselves as behaving in ways consistent with the demands of justice, but are simply unwilling to engage in an inquiry oriented towards what this requires. Consider, for instance, persons who engage in charity with the intention of improving the situation of persons for whose disadvantaged conditions they are (at least partially) responsible. Such persons see themselves as acting justly, perhaps even beyond what they are required to do. However, in many cases, they simply lack the motivation to try and understand the more complex political actions they ought to undertake in order to dismantle structural injustice. Self-interest does not play a role directly in determining their behaviour. Rather, it enters at a further level, insofar as beliefs about how to act are influenced by the need for epistemic avoidance.

\section{(5) The Deliberative Costs of Competence-Based Exclusion}

In the preceding two sections, I have demonstrated why the inclusion of disadvantaged groups in deliberation over their interests is necessary. The third section defended such inclusion by appealing to the necessary interlocutor principle. The fourth section went on to argue that that members of socially privileged groups were particularly less likely to access the interests of 
disadvantaged persons. Why would epistocracy affect a political system's capacity to satisfy the necessary interlocutor principle or mitigate epistemic avoidance? In what follows, I pay closer attention to the deliberative impact of an epistocratic political arrangement.

The relationship between deliberation and voting power can be conceptualised in two ways. The first approach suggests that reduction in voting power does not block persons from contributing to the discursive process. Mill, for instance, urged that even though illiterate persons ought to not have the franchise, they should have a role in shaping public opinion and influencing electors by participating in public discourse. Part of his defence of the open ballot was grounded in the need for disenfranchised voters to engage with voters and demand justification for how they had voted (1859, p. 490). Would this not open the way for suggesting that such persons, if competent enough to influence voters, could be deemed competent enough to also exercise the franchise themselves? Mill thought otherwise:

This argument is specious, and I once thought it conclusive. It now appears to me fallacious. All who are fit to influence electors are not, for that reason, fit to be themselves electors. This last is a much greater power than the former, and those may be ripe for the minor function who could not as yet be safely trusted with the superior (1859, p. 334).

On this account, then, disenfranchisement or the receipt of fewer votes merely deprives persons from taking final decisions on political issues. It does not hinder persons from influencing such decisions by contributing to deliberation on them.

Against this view, one might insist that the reduction of voting power-either through disenfranchisement or by receiving fewer votes than others-lowers persons' ability to participate in political deliberation. In other words, loss of one's ability to contribute discursively is a necessary by-product of the exclusion demanded by epistocratic arrangements. Why this might be the case, though, has not been adequately explored. In what follows, I examine two mechanisms that might underlie this view: the strategic incentive effect and the devaluation effect. I argue that the latter provides a more compelling approach towards understanding the nexus between voting power and deliberation.

\subsection{The Strategic Incentive Effect}

Why, Landemore asks, would an oligarchy initially made up of a cognitively diverse set of decision-makers fail over time to retain the diversity available in the larger population? She argues that 'absent democratic accountability and some form of influence of the larger public opinion on their decision process, the group of oligarchs has no incentive to maintain this initial degree of cognitive diversity' (emphasis mine, 2013, p. 107). In other words, decision-makers would fail to take what is epistemically valuable from those outside because there is no incentive for them to enrich themselves and avoid epistemic costs. When decision-makers are democratically accountable, they have a strategic incentive to engage with the wider population. 
Epistemic avoidance means that privileged persons have good reason to not engage with those who are disadvantaged. Such disengagement becomes considerably easier under an epistocratic arrangement. This is because epistocracy precludes the possibility that those disenfranchised would have a decisive say in political decisions. This argument does not rely upon a view of epistocrats as self-interested. Epistocrats may find it easier to ignore disadvantaged persons not because doing so helps serve their own interests better. Rather, even well-meaning epistocrats, who wish to act in the interests of disadvantaged persons, would find it easier to ignore those who do not have a vote. If the disadvantaged had a vote, this would provide a reason for privileged persons to engage with them in order to persuade them to vote for better outcomes. In doing so, privileged persons would be more likely to engage with the claims of disadvantaged persons about their own interests. However, epistocracy makes it less likely that this engagement would take place, by allowing epistocrats to bypass concerns of disenfranchised persons without having to worry that this would affect the realisation of their preferred decision. All else equal, then, epistemic avoidance is more likely to be exacerbated by epistocracy.

Note that this argument has its limitations. Enfranchisement can provide a strategic incentive for engagement only insofar as certain groups can influence electoral outcomes. Indeed, the importance of this point should not be underestimated. Even numerically small groups can become important depending on contingent features of a political system. In a contest with several candidates or parties, even relatively small groups can become a political salient force, forcing consideration with their claims. Further, it is possible to design democratic systems in a way that maximises such incentive, and, therefore engagement with different groups (James, 2008). Nevertheless, there are limits to how much engagement a political system can induce by linking these to strategic incentives. Do we assume that where strategic reasons for such engagement do not obtain, persons' claims about their interests will fail to receive any consideration? I do not wish to take the argument so far. Rather, let us grant that though less likely, enfranchised persons will engage with disenfranchised persons, and listen to their claims about their interests. I argue that such deliberation is likely to be vitiated by the devaluation entailed by competence-based disenfranchisement.

\section{(1) The Devaluation Effect}

Epistocracy is likely to undermine the evaluation of disadvantaged persons' claims about their interests because of the epistemic categorisation or labelling that it involves. Such labelling is likely to vitiate deliberation over the interests of persons categorised as incompetent, or less competent than others by devaluing their discursive contributions.

The process of categorizing persons involves paying attention to some features in a selective manner, sorting them along those rather than others. If every feature were incorporated in categorisation, then there would be as many categories as features, making categories altogether redundant. But in categorising persons as politically competent or incompetent, we are unable to track several relevant things. This binary is unable to account for the range of competencies and the degree to which these are present in persons. Suppose Miller knows a lot about his economic interests and can make considerable contributions towards the formulation 
of fiscal policies. A competence test determines that Miller is disqualified from voting because he lacks knowledge about the structure of government, and how representatives function within it. However, this determination is unable to track ways in which Miller can contribute. It devalues his status as a contributor, classifying him as incompetent without sufficiently accounting for his ability to act as a knower in relation to economic policies.

Contrast the above case with the case of the partially competent driver. Suppose Noddy knows how to use a clutch and apply the brakes to a car. But he is hopeless at steering the car. A driving test that he must pass determines that he is unqualified to drive as a result of his inability to steer. Noddy's claim that he can, nevertheless, brake and accelerate is irrelevant. These competencies have no claim to recognition or value in the absence of the ability to steer. We are fully justified in discounting Noddy's knowledge-claims in those limited respects. Miller's knowledge-claim about economic policies is not useless like Noddy's one about the ability to apply brakes despite lacking other abilities needed to drive. It makes no sense to speak of braking independent of the ability to drive in a way that it is perfectly sensible to suggest that the assessment of economic policies is independent of the exercise of voting. Thus, the inability to vote as a result of lack of some competencies should not discount one's claim to knowledge in assessing economic policies.

The categorisation of persons as politically competent or incompetent would, therefore, be an epistemically inadequate exercise. One might concede that it fails to do justice to the wide range of competencies relevant to political judgment, but how does this affect the process of evaluating epistemic claims made by the disenfranchised? To see how, it is important to understand what the act of categorising involves. The standard understanding suggests that categorising involves identifying shared features in objects or persons, and grouping them according to these, differentiating them from things or persons that have other shared features. On this view, the act of categorising simply maps on to already existing features, and emphasises extant commonalities. However, this ignores ways in which the act of categorisation also structures our responses and preferences in relation to those objects. When I classify some apples as 'good' and others as 'bad', I make it likelier that persons would prefer the former rather than the latter. Thus, the very act of categorising persons according to their levels of political competence is a political intervention with consequences for how we engage with persons. That some groups of persons are widely known as 'incompetent' under the epistocratic regime is likely to vitiate deliberation with such persons. ${ }^{\mathrm{xv}}$ The urgency given to their claims, the seriousness with which they are treated, and our evaluation of their validity, are likely to be undermined by the fact that their makers are deemed 'incompetent'.

Epistocracy does not need to conjure up the epistemically damaging consequences I have warned of. Disadvantaged groups are in any case susceptible to epistemic injustice, or the risk of harm in their capacity as knowers (Fricker, 2007). They suffer credibility deficits due to hearers' prejudices about their social identity. Epistemic labelling would further entrench, or worsen, epistemic injustices to which disadvantaged groups are already subject. Empirical research demonstrates how persons who hold prejudices are more prone to acting in discriminatory ways when they feel their views are objective (Uhlmann and Cohen, 2007). 
Epistocratic categorisation is likely, therefore, to fuel biased judgments during engagement with disadvantaged groups.

The preceding comments have focused on ways in which epistocracy would affect others' engagement with persons it would disadvantage. A second way in which epistocracy is likely to affect deliberation is through its internal effects on disadvantaged persons. Firstly, being categorised in this way could lead disenfranchised persons to treat their own justified claims with less credibility than they actually deserve. As Miranda Fricker (2007, p. 49) argues, 'If I am subject to suspicion, exclusion, even ridicule when I put forth my knowledge in cooperative inquiry, then I may give up the belief, or the justification for it, in spite of my evidence'. In other words, being stigmatised as incompetent can lead to epistemic injustice by an agent against herself, and not just from external others. On the other hand, being stigmatised in this manner might have detrimental epistemic effects for a person even when she does not internalise the stereotypes they perpetuate. She might come to recognise that even her valid claims are dismissed because she is viewed as an incompetent agent. This might lead her to develop a 'thick skin' as a defence mechanism. But in doing so, she can isolate herself epistemically, making it harder to sift her justified claims from unjustified ones. The epistemic trust and perceived reliability necessary for changing one's mind is missing in such situations because of the agent's history of being unfairly marginalised. This can result in situations where disadvantaged actors hold epistemically inferior beliefs because they are deprived of an environment where they could subject them to fair assessment.

Further, epistemic labelling could affect an epistemic agent by stifling her motivation to engage in cooperative inquiry. If she internalises her own purported inferiority as an epistemic agent, she could lose the motivation to press her claims on others. Epistemic labelling can also sap one's motivation in another way. The stigma it perpetuates can be damaging to persons' sense of worth. They are likely to protect their self-esteem by devaluing the domain where they fare poorly (Major and Schmader, 1998; Steele, 1997). That is, they may decide to disengage their sense of worth from achievement in that domain. But doing so harms their potential for achievement even further. Insofar as motivation is necessary for good epistemic performance, they could bind themselves to a feedback loop that perpetuates failure.

Jason Brennan has already responded to one version of such an argument. That argument urges that disenfranchisement commits an expressive harm by suggesting that some persons are less worthy of our respect than others. Brennan suggests that the impact of epistocracy is limited in expressing disrespect for persons who warrant it qua voters. It does not follow from this that persons do not generally deserve equal respect. It is fallacious to infer from our judgment that they are incompetent voters that they are, therefore, of less moral worth. If such an inference is made, it is arbitrary. It relies on a contingent and implausible social meaning we attach to enfranchisement, where voting is wrongly considered a mark of dignity (2016, pp. 127-30). After all, such respect for persons could be expressed in other ways that do not involve subjecting them and others to negative consequences. 
My argument avoids this objection by focusing narrowly, like Brennan, on what disenfranchisement expresses about persons' epistemic abilities in relation to politics, rather than their moral worth per se. Contra Brennan, I agree that disenfranchisement of person is likely to have consequences for how persons' moral worth is perceived. A spill-over effect from their status as political knowers to perceptions of their moral status is very likely. I also think it is unsatisfactory to claim a contingent relationship between political status and moral worth. If anything, this makes Brennan guilty of methodological duplicitousness, selectively viewing parts of the social world as contingent, and others as abiding. However, my case does not hinge upon the broader consequences of disenfranchisement for persons' moral status. Rather, my argument insists that as a categorisation of what people know about politics, the epistocracy's binary of 'competent' versus 'incompetent' is misleading. It imposes the label of 'incompetent' upon disadvantaged persons without doing justice to, and therefore undermining, their potential contribution as knowers.

Further, my emphasis on the devaluation effect does not appeal to any intrinsic harm of disenfranchisement for peoples' status as political agents. Melissa Schwartzberg makes such an argument when she urges that any departure from equal votes for all constitutes an epistemic injustice. She argues that this is because such departures fail to recognise our equal status as contributors to the deliberative process (2014, pp. 111-18. Also see Christiano, 1996). While I agree with Schwartzberg, my argument focuses elsewhere: on the outcome of inadequate epistemic labelling rather than why it is intrinsically harmful. This allows us, consistent with the aim of this article, to engage with epistocracy on its own terms-by appealing to the epistemically weak outcomes it produces.

\section{(6) Conclusion}

This article has suggested that the epistemic case against epistocracy can shed its reliance on the best judge principle. Instead, it is possible to insist that merely that any group of persons ought to be included in deliberation over their own interests. Further, it has underscored the need for inclusive deliberation by emphasising the distinctive epistemic obstacles faced by socially privileged persons. It argued that, in addition to the necessary interlocutor principle, privileged demographic groups are also subject to the challenges of epistemic avoidance, necessitating the deliberative inclusion of disadvantaged groups. Finally, it suggested that the kind of deliberation demanded by such arguments is likely to be vitiated under epistocratic arrangements. The devaluation entailed by competence-based categorisation would threaten deliberation with persons excluded or disadvantaged in an epistocracy. These arguments, then, strengthen the epistemic case against competence-based exclusion from political power.

\footnotetext{
i Depending on how demanding one's threshold for competence is, this test may be compatible with what Lippert-Rasmussen calls an ‘underprivileged knowledge status claim' (2012, p. 248). This claim insists that, for any demos, there are groups slightly smaller than the demos (for instance, the demos as a whole excluding some particular group), that have epistemic warrant to rule. We might stipulate fairly minimalist standards for competence such that only a small group or groups of persons have an underprivileged knowledge status. ii See, for instance, Mill’s proposal on plural voting (Mill, 1859, pp. 324-25).
} 
iii I exclude discussions about judicial review and whether this requires the selection of competent jurists. It is theoretically possible for design judicial institutions in an inclusive manner; for instance, by establishing randomly selected juries of laypersons for constitutional matters. However, before we begin addressing this question, we would have to first address the prior question about the justifiability of judicial review of legislation.

iv This is, of course, on our most optimistic understanding of the test designers' intentions. The point applies with even greater force if we factor in the partisan exclusions that such tests are likely to generate.

v The assumption of temporariness, pivotal to this account, underpinned Mill's argument for the educational qualification. While acknowledging that society could not presently ensure it was attainable by all, he insisted that this qualification would soon exclude only those who chose to not undertake effort for its realisation. (Mill, 1859, p. 471).

vi See Muhammad Nasir Mahmood v. Federation of Pakistan (2011) in the Supreme Court of Pakistan; Rajbala v. State of Haryana (2016) 1 SCC 463 in the Supreme Court of India. Indeed, public office qualifications raise somewhat different questions from those pertaining to restrictions on the vote. The point, though, is that the governments in both countries insisted that the exclusion of uneducated persons from a share in political power was justified even despite their acknowledgment that many such persons had no access to formal education.

vii For a defence of the theorem in the context of democratic politics, see Landemore, 2013.

viii I agree with Landemore that the correlation between group size and cognitive diversity is not always verified, but that it is generally more plausible than the reverse assumption that cognitive diversity decreases as the number of people go down.

ix So far, the response from the epistocratic side has been far from satisfactory. Jason Brennan, for instance, rejects Landemore's suggestion that deliberative procedures ought to be appropriately reformed in order to perform the epistemic potential she attributes to them. He suggests that such arguments rely on a priori understandings of deliberation and are insensitive to its actual pathologies. But this seems to make Brennan guilty of methodological doublespeak. His insistence upon a realist approach towards democracy as it exists contrasts starkly with an idealized view of epistocratic institutions. If we must contend with democracy as it exists, then perhaps we ought to compare it to epistocracy as it existed under, say, colonialism, or the regime of literacy qualifications for suffrage in mid- $20^{\text {th }}$ Century America. On the other hand, if we believe these were bad cases of epistocracy, and epistocracy proper would fare better, then there is no reason to discount such arguments for democracy, properly designed, as Brennan does. In other words, comparisons of the epistemic capacities of democracy and epistocracy must proceed either from equally realist perspectives, or permit both to reject their contingent features.

${ }^{x}$ For the role of the best judge principle in grounding respect for democratic procedures, see Schwartzberg, 2014, pp. 112-14; Dahl, 1989, p. 105.

xi For an overview of such arguments, see Goodin, 1990.

xii Although Landemore does not address this directly, I believe a principle of this sort is closer to her views on deliberation and the perspectival grain of truth different people hold. See Landemore, 2013, pp. 97-104. As such, the recommendation for shedding the best judge principle is largely aimed at Estlund's demographic objection.

xiii This example is modelled after that offered by Hayward, 2017, p. 398.

xiv For a similar point, see Stanley, 2015.

${ }^{\mathrm{xv}}$ It is possible to devise schemes that do not admit such distinctions. For instance, lotteries have been advanced as way of enhancing the epistemic quality of decision-making assemblies. However, since they do not view some persons as more competent relative to others, urging the transfer of power to superior agents, I do not consider such proposals as epistocratic. One may view those admitted by a lottery as having achieved greater epistemic insight after participating in the assembly's deliberations, but this does not involve stipulating prior standards of competence which determine who could be included or excluded from the decision-making body.

\title{
Acknowledgments
}

\author{
I am grateful to Matthias Brinkmann, Sarah Bufkin, Liz Frazer, David Froomkin, Sanjana \\ Govindarajan, Hélène Landemore, David Miller, Bruno Leipold, David Owen, Ketan \\ Ramakrishnan and Ben Saunders for valuable feedback on this paper. I received very helpful \\ feedback on a previous draft from participants at the Workshop on Social and Political \\ Epistemology at the University of Copenhagen. I am also grateful to Annabelle Lever and \\ two anonymous reviewers of this journal for their comments.
}




\section{Notes on the Contributor}

Udit Bhatia is a Lecturer in Political Theory at Lady Margaret Hall, University of Oxford. He is a doctoral candidate in the Department of Politics and International Relations at Oxford, and his research interests lie at the intersections of democratic theory, political representation and social epistemology. From October 2018, he will be a Junior Research Fellow in Politics at Jesus College, Oxford.

\section{References}

Brennan, J. (2011). The Right to a Competent Electorate. The Philosophical Quarterly, 61 (245), 700-724. https://doi.org/10.1111/j.1467-9213.2011.699.x

Brennan, J. (2016). Against Democracy. Princeton: Princeton University Press.

Brennan, J. (2018). Does the Demographic Objection to Epistocracy Succeed? Res Publica, 24(1), 53-71. https://doi.org/10.1007/s11158-017-9385-y

Christiano, T. (1996). The Rule of the Many: Fundamental Issues in Democratic Theory. Boulder: Westview Press.

Dahl, R.A. (1989). Democracy and Its Critics. New Haven: Yale University Press.

Dana, J., Weber, R.A., \& Kuang, J.X. (2007). Exploiting Moral Wiggle Room: Experiments Demonstrating an Illusory Preference for Fairness. Economic Theory, 33(1), 67-80. https://doi.org/10.1007/s00199-006-0153-z

Emler, N. \& Frazer, E. (1999). Politics: The Education Effect. Oxford Review of Education, 25(1-2), 251-273. https://doi.org/10.1080/030549899104242

Estlund, D.M. (2003). Why Not Epistocracy? In N. Reshotko (Ed.), Desire, Identity and Existence: Essays in Honor of T.M. Penner (pp. 53-69). Edmonton, Alberta: Academic Printing and Publishing.

Estlund, D.M. (2008). Democratic Authority: A Philosophical Framework. Princeton, NJ: Princeton University Press.

Freddi, E. (2017). Do People Avoid Morally Relevant Information? Evidence from the Refugee Crisis. CentER Discussion Paper, 2017-034. Retrieved from https://papers.ssrn.com/sol3/papers.cfm?abstract_id=3040531

Fricker, M. (2007). Epistemic Injustice: Power and the Ethics of Knowing. Oxford: Oxford University Press. 
Goodin, R. (1990). Liberalism and the Best-Judge Principle. Political Studies, 38(2), 181195. https://doi.org/10.1111/j.1467-9248.1990.tb01487.x

Graham, G. (2002). The Case Against a Democratic State: An Essay in Cultural Criticism. Charlottesville: Imprint Academic.

Granderson, LZ. (2011, April 12). Don’t Let Ignorant People Vote. CNN Opinion. Retrieved from http://edition.cnn.com/2011/OPINION/04/12/granderson.ignorant.vote/index.html

Guston, D.H. (2005). On Consensus and Voting in Science: From Asilomar to the National Toxicology Program. In S. Frickel and K. Moore (Eds.), The New Political Sociology of Science (pp. 378-404). Madison: University of Wisconsin Press.

Harsanyi, D. (2016, May 20). We must weed out ignorant Americans from the electorate. Washington Post Opinion. Retrieved from https://www.washingtonpost.com/opinions/

Hayward, C.R. (2017). Responsibility and Ignorance: On Dismantling Structural Injustice. The Journal of Politics 79(2), 396-408. https://doi.org/10.1086/688355

James, M.R. (2008). Diversity, Deliberation, and the Concepts of Constituency. Polity, 40(2), 229-37. https://doi.org/10.1057/palgrave.polity.2300098

Landemore, H. (2012). Why the Many Are Smarter than the Few and Why It Matters. Journal of Public Deliberation, 8(1). Retrieved from:

https://www.publicdeliberation.net/cgi/viewcontent.cgi?article=1190\&context=jpd

Landemore, H. (2013). Democratic Reason: Politics, Collective Intelligence, and the Rule of the Many. Princeton: Princeton University Press.

Landemore, H. (2014). Yes, We Can (Make It Up on Volume): Answers to Critics. Critical Review, 26 (1-2), 184-237. https://doi.org/10.1080/08913811.2014.940780

Lippert-Rasmussen, K. (2012). Estlund on Epistocracy: A Critique. Res Publica, 18(3), 241258. https://doi.org/10.1007/s11158-012-9179-1

Major, B., \& Schmader, T. (1998). Coping with Stigma through Psychological Disengagement. In J.K. Swim \& C. Stangor (Eds.), Prejudice: The Target's Perspective (pp. 219-241). San Diego, CA: Academic Press.

Medina, J. (2012). The Epistemology of Resistance: Gender and Racial Oppression, Epistemic Injustice, and the Social Imagination. Oxford: Oxford University Press.

Mill, J. S. (1859). Thoughts on Parliamentary Reform. In J. M. Robson (Ed.), The Collected Works of John Stuart Mill, Volume XIX, Part II. Toronto Press, London: Routledge and Kegan Paul. 
Miller, G., \& Whitford, A. (2016). Above Politics: Bureaucratic Discretion and Credible Commitment. Cambridge: Cambridge University Press.

Mills, C.W. (2007). White Ignorance. In S. Sullivan \& N. Tuana (Eds.), Race and Epistemologies of Ignorance (pp. 13-38). Albany, NY: SUNY Press.

Moore, A. (2017). Critical Elitism: Deliberation, Democracy, and the Problem of Expertise. Cambridge: Cambridge University Press.

Raz, J. (1986). The Morality of Freedom. Oxford: Oxford University Press.

Richeson, J.A., \& Shelton, J.N. (2007). Negotiating interracial interactions: Costs, consequences, and possibilities. Current Directions in Psychological Science, 16(6), 316320. https://doi.org/10.1111/j.1467-8721.2007.00528.x

Schwartzberg, M. (2014). Counting the Many: The Origins and Limits of Supermajority Rule. Cambridge: Cambridge University Press.

Spiekermann, K. (2016). Four Types of Moral Wriggle Room: Uncovering Mechanisms of Racial Discrimination. In M.S. Brady \& M. Fricker (Eds.), The Epistemic Life of Groups: Essays in the Epistemology of Collectives. Oxford: Oxford University Press.

Stanley, J. (2015). How Propaganda Works. Princeton, NJ: Princeton University Press.

Steele, C. (1997). A Threat in the Air: How Stereotypes Shape Intellectual Identity and Performance. American Psychologist, 52(6), 613-629. https://doi.org/10.1037/0003066X.52.6.613

Uhlmann, E.L., \& Cohen, G.L. (2007). "I think it, therefore it’s true”: Effects of selfperceived objectivity on hiring discrimination. Organizational Behavior and Human Decision Processes, 104(2), 207-223. https://doi.org/10.1016/j.obhdp.2007.07.001

United States House of Representatives. (1866). 39th Congress, 1st Session, 407 (Frederick A. Pike). Congressional Globe. Washington: Library of Congress.

Verba, S., Schlozman, K.L., Brady, H., \& Nie, N.H. (1993). Race, Ethnicity and Political Resources: Participation in the United States. British Journal of Political Science, 23, 453-497. https://doi.org/10.1017/S0007123400006694

Wilkinson, T.M. (1996). Judging Our Own Good. Australasian Journal of Philosophy, 74(3), 488-494. https://doi.org/10.1080/00048409612347461

Ziliotti, E., \& Bell, D.A. (2014). Should Voters Be Tested? The Huffington Post. Retrieved from china_b_4776362.html https://www.huffingtonpost.com/daniel-a-bell/voter-test-europe- 